\title{
As questões: mulber, biografia e literatura nos escritos em prosa de Ana Cristina Cesar
}

Clara de Andrade Alvim

Para tratar dessas questões não vou me utilizar do ensaio Literatura não é documento - publicado ainda em vida de Ana Cristina - muito mais em razão do espaço que requer esta breve com unicação* do que pelo interesse que também ele oferece para o melhor esclarecimento da pergunta que a obcedava: o que é literatura. Decorrente de uma pesquisa sobre documentários cinematográf icos que tratavam de autores ou de obras literárias, produzidas no Brasil, o livro se concentra fundamentalmente em compreender como e quando conseguem tais documentários destacar-se do real e confundir-se ao mesmo tempo com ele. Em suas palavras: "há tensões neste jogo, e tensões que não limpam a função documental, com todo o seu poder de registro verdadeiro, mas se fazem em seu interior".

Essa referência me bastará, entretanto, para desde já dar idéia da importância atribuída por Ana Cristina ao que chama de jogo, contraponto, fusão entre o real - especialmente o biográfico - e a ficção, invenção. $\mathrm{E}$ à tensão, à faísca da literatura brotando desta armadilha ao leitor, ou interlocutor - a outra ponta da me ada sempre presente no seu entender da lit eratura.

Quero, igualmente, desde logo deixar explicitado o que ap enas ficará sugerido ao longo deste texto, embora me pareça o que existe de mais relevante nos livros publicados postumamente, Escritos da Inglaterra e Escritos no Rio, de Ana Cristina: é que, muito mais do que para as afiadíssimas observações sobre seus objetos de int eresse, o leitor deverá atentar para a estrutura, a construção desses 
escritos em prosa cuja descentralização, fingimento, constante a rmadilha revelam muito a sua poética, o seu sentimento da literat ura. Construção correspondente a uma afirmação corrente nesses escritos, dita através das mais diversas formas: "não vou chegar nunca na verdade do meu texto" (Escritos no Rio).

No artigo "Literatura e Mulher: Essa Palavra de Luxo", publicado em 1979 (Escritos no Rio), uma resenha, que lhe fora encomendada sobre as antologias das consagradas poetisas Cecília Me ireles e Henriqueta Lisboa, se transforma na montagem da fala de diversas personas (dramatis personae) que se contradizem entre si, em referência a uma série de perguntas - contidas na primeira fala ou fala I. Essas perguntas se resumiriam na questão muito presente naquele momento áureo do feminismo no Brasil: o de distinguir uma poesia feminina, em sua natureza, da poesia masc ulina.

A fala II, cuja autoria facilmente se deixa adivinhar como a da própria autora, afirma que, do ponto de vista popular — do se nso comum - mulher e poesia se identificam: a contradição, o in efável, o profundo lhes seria inerente. E constata que a crítica er udita realizada sobre a poesia de Cecília Meireles e Henriqueta Li sboa não se afasta desta mesma concepção. $O$ suave, o natural das imagens estetizantes frequente nas obras dessas poetisas, a sua di cção nobre - ainda que se trate da realização de poesia, e da poesia de mulheres - indica, ao ver desta fala, que deixaram em sua obra uma marca feminina sem jamais se colocarem como mulheres, nem se abrirem para a modernidade.

As falas III, IV, V e VI são vozes dos comentadores eruditos dessas poetisas. Dizem que Cecília levita como puro espírito, que a sua poesia só poderia ser obra de mulher, a partir de perspectivas que os homens não teriam. A fala VI, reconhecendo que há elementos comuns entre a poesia de Cecília Meireles e a de Henriqueta Lisboa, nega que esse encontro se localize na feminil idade de suas respectivas poesias. E afirma que "a idéia de procurar 
uma poesia feminina é uma idéia de homens", manifestação do complexo de superioridade de alguns críticos que é preciso abandonar. Esta voz conclui convidando:"Diante de um livro de versos, não olhemos quem o escreveu, abandonemo-nos ao prazer".

Em outro tom - que mistura seriedade e irreverência segue a fala VII, em que se destaca a afirmação de que - sem condescendência - é importante o fato ainda raro de serem $\mathrm{m}$ ulheres efetivamente escritoras as duas poetisas em causa; mas que, além de haverem elas passado ao largo da modernidade em tempos do modernismo brasileiro, abriram o caminho para uma recepção que feminiza (recebe como inefável, sutil, elevada) a produção feminina.

Outras falas se alternam na discussão do tema, e a número $\mathrm{X}$ volta a ser a de Ana Cristina, tratando de Adélia Prado, em quem reconhece a passagem para a modernidade: Adélia, a seu ver, s upera "a modernização do universo imagético pela feminização temática. Ser mulher é tema e motivo para a sua produção". Como Henriqueta Lisboa, ela revela a "incontornável" inveja pelo Irmão Maior - Carlos Drummond de Andrade - mas, aqui, a poesia é desmetaforizada, despoetizada no sentido da recusa do estilo sublime, substituído pelo mesclado, impuro. (Em outro capítulo dos "Escritos no Rio ", datado de 1982, Ana Cristina se mostra de acordo com a opinião expressada pela brasilianista Sylvia Riverrun, da Universidade do Texas, segundo a qual Cecília e Henriqueta escreveriam sem se declararem, eludindo a sua condição de mulher, enquanto Adélia apontaria para outra via: a questão passa para dentro do texto).

A última fala - acrescentada dois anos depois da elabor ação das anteriores - intitula-se "Errata". Passado o tempo e havendo o feminismo ganhado terreno, a poesia feminina teria, agora, se tornado na opinião de Ana Cristina "aquela que berra na sua cara tudo o que você jamais poderia esperar da senhora sua tia". 
Invertendo os pressupostos bem-comportados da linhagem feminina, tal poética, a seu ver, "recorta novamente o exato espaço e o tom em que a mulher (agora moderna) deve fazer literatura". A ssim, no final deste texto recortado em fragmentos, o problema se repõe.

Em outros dos "Escritos do Rio", Ana Cristina volta à questão. Quando acompanha o desenvolvimento da relação de Sylvia Riverrun com o feminismo e com o interesse pela literatura feminina ( "Riocorrente, depois de Eva e Adão...", publicado em 1982), indaga se a imposição feminista de escrever cientificamente, impessoalmente não estaria recalcando na própria Sylvia a sua po rção-mulher. E constata como positiva uma evolução dessa autora em direção à liberação do tom acadêmico; um encaminhamento para o que chama de um texto mais "frívolo, na exploração da experiência".

Não seria melhor, então, diz Ana Cristina, deixar o problema do feminino no texto literário "à deriva, errante, conforme nos s opre o que há de feminino na linguagem?"

Neste mesmo sentido, mas sem abandonar — antes muito pelo contrário - o interesse em desvendar em que consiste a po rção-mulher na linguagem, no capítulo intitulado "Excesso Inqui etante", de 1982 ((E.R).), Ana Cristina assim descreve o escrever femininamente no romance de Marilene Felinto - As Mulheres do Tijucopapo: "forma errante, descontínua, desnivelada, expondo com intensidade muito sentimento em estado bruto... dirigindo-se ete $\mathbf{r}$ namente a um interlocutor, falando sempre "para alguém", como "numa carta imensa". Mas, diz ela: "ao mesmo tempo esse femin ino transborda um excesso inquietante. Ao longo do livro, trava-se uma luta com esse feminino excessivo, com esse a-mais, porque o excesso se situa à beira de uma amedrontada indefinição, à beira de uma impossibilidade de afirmar, afirmar-se, dar forma, acabar-se". 
do turvo como um desejo de literatura, e a confissão de Marilene Felinto de recontar a narrativa através de uma carta em inglês como o de "separar a autora de falar de si na mesma língua das pessoas a quem se dirige".

Literatura, diz Ana, "é um material como que estrangeiro, que nos separa dessa proximidade do sentimento bruto, nos descola de nós e da língua de nossas pessoas".

No Depoimento - de 1983 - dado no curso "Literatura de Mulheres no Brasil" ( (E.R).) sobre os seus próprios poemas, que têm um lado de cartas, diários íntimos, correspondências, revelações e ocultamentos, afirma que "a intenção do texto é escapar à confidência, à verdade - menos porque se quer do que pela i mpossibilidade de comunicar a verdade literariame nte".

O literário, para Ana Cristina, está ligado ao moderno - ao corte, ao fragmento, ao escapar à verdade. Para ela, não existe e ntrelinha; o texto é uma materialidade - tudo está ali. A poesia não esconde - revela. A contradição é aparente: escapar é dizer.

Entretanto, os seus poemas pretendem puxar até o limite o desejo do leitor de acesso a algo que não está no texto, e esta é a sua armadilha.

$\mathrm{Na}$ perseguição de seu interesse pelo que distingue o biográfico do literário e, sobretudo, de como se elabora o literário sobre o biográfico, Ana Cristina transcreve, no capítulo que tem por título "Para conseguir suportar essa tonteira", de 1976 ((E.R).), a entrevista que fez com Carlos Sussekind - autor do livro Armadilha para Lamartine. $\mathrm{Na}$ introdução à entrevista, a autora já aponta a parte da obra que, a seu ver, "é evidentemente literatura", escrita, segundo ela, "sob o signo da máscara e da representação". Referi ndo-se à outra parte, diz que "esta não tem qualquer intenção liter ária". De tão cotidiano, esse texto parece ser " cópia do real".

A entrevistadora pergunta a Carlos Sussekind qual o seu entendimento sobre a relação entre ficção e biografia, entre liter a- 
tura e documento. Das respostas, realço aqueles pontos que coincidem não só com as preocupações — digamos — teóricas de Ana Cristina, como com aquelas que regem fundamentalmente sua própria literatura.

Em primeiro lugar, a percepção, revelada pelo entrevistado, das potencialidades que oferece a escrita biográfica para transformar-se em literatura, indicando, nesse sentido, a particularidade desse tipo de registro - o diário - de correr em todas as direções, sem um critério definido: a sua falta de unidade. E, também, a existência, nessas anotações do dia a dia, de pontos de interesse que valem a pena de serem aproximados - o que sugere a técnica da montagem. Mas não só: o registro autobiográfico do cotidiano s ugere, sobretudo, a possibilidade da sua reelaboração ou, se quise rmos, a de sua reinvenção - preservando-se aí, justamente, as c aracterísticas da escrita não literária.

Em outro texto - "Um livro cinematográfico e um filme literário” ((E.R).), de 1976, Ana Cristina afirma, a propósito do livro de Carlos Sussekind que "a impressão de documento é parte do fingimento literário".

Em segundo lugar, destaco aquilo que o entrevistado chama de "a troca entre os dois textos", e que não trata mais do trabalho de elaboração sobre a escrita biográfica e sua transformação no literário. A questão, agora, é a da intromissão do texto completamente inventado - digamos estritamente literário - no elaborado sobre o biográfico; e vice-versa. Ou da justaposição dos dois, quando mais convenha.

No livro Escritos da Inglaterra, que contém estudos e reflexões sobre a teoria e a prática da tradução, assim como na sua tradução anotada do conto "Bliss", de Katherine Mansfield, existem, ta mbém, indicações preciosas sobre a importância que atribui Ana Cristina à potencialidade de certa matéria não literária. 
colar-se na biografia do texto a ser traduzido, para aí apreender suas fundamentais direções literárias, que estarão refletidas - e mbora ocultas e mascaradas - na literatura que se propõe a traduzir. Espelho contra espelho - encontramos Ana Cristina reproduzi ndo seu próprio processo de escrever.

Sobre as notas que acompanham a tradução - antes de passar ao trabalho que chama de sua classificação, mas que se constitui, na verdade, em uma descrição e análise brilhantes de sua m aneira de traduzir - ela observa que têm um "movimento desce ntralizador". E, a seguir, afirma "a necessidade de uma síntese que vá invertendo esse processo ou, pelo menos, de algo estrutural que possa evidenciar o padrão oculto por detrás de ssas oitenta notas".

Tal padrão oculto regeu a sua tradução. Vejo aí uma pista esclarecedora para a maior consciência do quebra-cabeças ou da armadilha em que se constitui a construção da literatura de Ana Cristina Cesar.

\section{Notas}

${ }^{*}$ Esse texto foi apresentado no Segundo Congresso Português de Literatura Brasileira, realizado na Universidade do Porto, em maio de 1997.

\section{Bibliografia}

CESAR, Ana Cristina. Literatura não é documento. Rio de Janeiro, MEC/FUNARTE, 1980.

. Escritos da Inglaterra. (Org. Armando Freitas Filho). São Paulo, Brasiliense, 1988.

- Escritos no Rio. (Org. Maria Luísa Cesar). Rio de Janeiro, São Paulo, ed.UFRJ/Brasiliense, 1993. 